\title{
Steroid Hormone Metabolites in Fish Urine-II Identification of Pregnanediol, Pregnanetriol and Androstenediol Isolated from the Urine of Carp
}

Tomoki YANO* and Shinya IsHio*

(Received June 10, 1978)

\begin{abstract}
The present investigation deals with the identification of progesterone metabolites in the urine of carp, Cyprinus carpio. The urine sample collected by inserting a catheter into the urinary bladder was passed through an Amberlite XAD-2 column. The steroids adsorbed on the column were eluted with methanol and hydrolyzed with $\beta$-glucuronidase and by solvolysis (ethylacetate$1 \mathrm{~N} \mathrm{H}_{2} \mathrm{SO}_{4}$ ). The liberated steroids were extracted with ethylacetate and converted to methoximetrimethylsilyl derivatives for gas liquid chromatographic (GLC) and mass spectrometric (MS) analyses.

The GLC separations were carried out on $1 \% \mathrm{OV}-1$ and $1 \% \mathrm{OV}-17$ columns. The two peaks observed on the progesterone metabolite region and the one peak in the 17-ketosteroid region on the chromatograms were identified as those of pregnanediol, pregnanetriol, and androstenediol by methylene unit value determination. Their identities were also established by GLC-Mass spectrometry.
\end{abstract}

The analysis of human urinary steroids has been extensively made to diagnose pregnancy and to study the dysfunction of endocrine organs. However, in fish, no investigation has been made in this field.

The procedure for the study of human urinary steroids was developed by HORNING et $a l^{1-31}$ based upon gas liquid chromatographic (GLC) separation of TMSi and MO-TMSi derivatives: Reactive hydroxyl groups were converted to TMSi groups and reactive ketone groups to methoximes; the products were characterized by determining methylene unit (MU) values with $1 \% \mathrm{OV}-1$ and $1 \%$ OV- 17 columns. In addition, the GLC-MS method introduced by RYHAGE ${ }^{4}$ has enabled steroid chemists to identify microgram and nanogram quantities of steroids from biological sources. The authors applied these methods to the analysis of urinary steroid metabolites in fish.

In our previous paper ${ }^{51}$, androsterone, etiocholanolone and dehydroepiandrosterone (DHEA) were identified as the major 17-ketosteroids in carp urine. The present paper deals with the identification of progesterone metabolites in the fish urine.

\section{Materials and Methods}

\section{Purification of Materials}

Methanol and ethylacetate (analytical reagent grade) were freshly distilled prior to use. Pyridine was refluxed over pellets of $\mathrm{KOH}$, distilled on fresh pellets and stored in a dark bottle. Standard samples of pregnanediol ( $5 \beta$-pregnan$3 \alpha, 20 \alpha$-diol), pregnanetriol (5 $\beta$-pregnan- $3 \alpha, 17 \alpha$, $20 \alpha$-triol), androstenediol (5-androsten-3 $\beta, 17 \beta$ diol) and cholesterol (5-cholestene-3 $\beta$-ol) were purchased from Sigma Chemical Co. and used without further purification because their homogeneities were confirmed both by thin layer chromatography and by GLC.

\section{Collection of Urine Samples}

The carp (body weight, 255 to $270 \mathrm{~g}$ ) was anaesthetized for $10 \mathrm{~min}$ in $30 \mathrm{ppm}$ quinaldine solution and inserted a silicone catheter into the urinary bladder. The fish was then transferred to a urine collecting apparatus $(30 \times 12 \times 12 \mathrm{~cm})^{51}$ which was provided with running dechlorinated tap water at a flow rate of $100 \mathrm{~m} / / \mathrm{min}$, and with adequate aeration. The free end of the silicone cannula was passed outside the fish chamber and attached to a ice-cooled receiver flask. The long and soft cannula $(30 \mathrm{~cm} \times 1 \mathrm{~mm}$ i.d.) permitted

* Lab. Fish. Chem., Fac. Agr., Kyushu Univ., Fukuoka 812, Japan (失野友紀・石尾真弥：九州大学農学 部水産化学教室). 
some freedom of movement for fish without displacing the catheter from the urinary bladder. The temperature of water was kept at $17 \pm 1^{\circ} \mathrm{C}$ throughout the experiment. The urine excreted for the first 24 hours was discarded in order to exclude the influence of diuretic stress ${ }^{61}$ which commonly follows the catheterization procedures, and the urine collected for the following 48 hours was used for the analyses.

\section{Hydrolysis of Conjugated Steroids}

The urine samples $(68-95 \mathrm{~m} l)$ collected from five male and four female carps were filtered and percholated through Amberlite XAD-2 columns (each ca. $2.5 \mathrm{~g}, 15 \mathrm{~cm} \times 0.5 \mathrm{~cm}$ i.d. $)^{7)}$ at a flow rate of about $0.5 \mathrm{ml} / \mathrm{min}$. After washing the column with $10 \mathrm{ml}$ of distilled water, the steroid conjugates were eluted with $12.5 \mathrm{~m} l$ of methanol. The eluate was dried under a stream of nitrogen gas and subjected to enzymatic hydrolysis and solvolysis according to the method of SAKAUCHI ${ }^{8}$ as follows: 1000 units of $\beta$-glucuronidase (ca. $16 \mathrm{mg}$, Sigma type I), $5 \mathrm{~m} l$ of $0.5 \mathrm{M}$ phosphate buffer ( $\mathrm{pH} \mathrm{6.0)}$ ) and a few drops of chloroform were added to the steroid residue dissolved in $25 \mathrm{~m} /$ of water, and the mixture was incubated for 24 hours at $37^{\circ} \mathrm{C}$ with constant shaking. After incubation, $25 \mathrm{~m} l$ of ethylacetate, $0.5 \mathrm{ml}$ of $2 \%$ formalin solution, $1.5 \mathrm{ml}$ of $50 \%$ $\mathrm{H}_{2} \mathrm{SO}_{4}$ solution and $6.25 \mathrm{~g}$ of sodium chloride were added and the mixture was shaken vigorously for 5 minutes, and gently for 43 hours at $33^{\circ} \mathrm{C}$.

The mixture was transferred to a separating funnel. The ethylacetate layer was reserved, whereas the remaining aqueous layer was reextracted with $25 \mathrm{~m} l$ of ethylacetate. The combined extracts were washed successively with five $7.5 \mathrm{~m} l$ portions of $8 \% \mathrm{NaOH}-10 \% \mathrm{NaCl}$ solution and three $7.5 \mathrm{~m} l$ portions of $10 \% \mathrm{NaCl}$ solution, then dried over anhydrous $\mathrm{Na}_{2} \mathrm{SO}_{4}$, and the solvent was removed in vacuo. The residue was dissolved in a minimal amount of ethylacetate and transferred to a small sample tube $(5 \mathrm{~cm} \times 5 \mathrm{~mm}$ i.d.) with a Teflon cap and dried up.

\section{Free Steroids}

The urine samples $(77 \mathrm{ml}, 92 \mathrm{~m} l)$ collected from one male and one female carp were filtered and diluted to $100 \mathrm{~m} l$ with distilled water. After adding $25 \mathrm{~g}$ of sodium chloride, the solution was transferred to a separating funnel and extracted twice with $100 \mathrm{~m} l$ of ethylacetate. The combined extracts were treated in the same way as described above.

\section{Preparation of TMSi and MO-TMSi Derivatives}

The preparation of derivatives was carried out following the procedures of HoRNING et al. ${ }^{2,31}$ The sample of carp urinary steroids (or a mixture of reference steroids, each approx. 1-2 $\mu \mathrm{g}$ ) was dissolved in $0.2 \mathrm{~m} l$ of dry pyridine containing $2 \mathrm{mg}$ of methoxylamine hydrochloride. The mixture was allowed to stand overnight at room temperature and then pyridine was removed under reduced pressure. The residue was extracted with $3 \mathrm{~m} l$ of ethylacetate, and the extract was washed with three $2 \mathrm{~m} l$ portions of $5 \% \mathrm{Na}_{2} \mathrm{CO}_{3}-10 \% \mathrm{NaCl}$ solution, dried with anhydrous $\mathrm{Na}_{2} \mathrm{SO}_{4}$ and concentrated to a small volume. The concentrate was transferred to a small sample tube, and the solvent was removed in vacuo. The residual contents were allowed to react with $20 \mu l$ of bis-trimethylsilylacetamide (BAS, Tokyo Chem. Product $\mathrm{Co}$.) for 1 hour in a tightly capped tube to prevent the entrance of moisture and the reaction mixture was subjected to GLC and GLC-MS analyses.

\section{Gas Liquid Chromatography}

Analytical separations were performed with a Shimazu model 4BMPF gas liquid chromatograph equipped with hydrogen flame ionization detectors. The columns were $3 \mathrm{~m} \times 4 \mathrm{~mm}$ glass coils and the phases employed were $1 \% \mathrm{OV}-1$ and $1 \% \mathrm{OV}-17$ on Shimalite W (acid washed, silanized, 80-100 mesh). The separations were carried out by temperature programming at $2^{\circ} \mathrm{C} / \mathrm{min}$ from $170^{\circ} \mathrm{C}$ for $\mathrm{OV}-1$ and from $200^{\circ} \mathrm{C}$ for $\mathrm{OV}-17$. Injection zone and detector were kept at $280^{\circ} \mathrm{C}$. The flow rate of nitrogen gas was $60 \mathrm{~m} / / \mathrm{min}$.

Suitable aliquots of sample were injected into the column with a microsyringe. TMSi and MO-TMSi derivatives were characterized by methylene unit (MU) values with $n$-alkanes as reference compounds.

\section{Gas Liquid Chromatography-Mass Spectrometry}

A Hitachi model RM-50GC gas liquid chromatograph-mass spectrometer with a $2 \mathrm{~m} \times 4 \mathrm{~mm}$ i.d. glass column packed with $1 \%$ OV-1 on Shimalite $\mathrm{W}$ was used. The flow rate of helium gas was ca. $30 \mathrm{~m} / \mathrm{min}$. The ionization potential and current were $50 \mathrm{ev}$ and $80 \mu \mathrm{A}$, respectively.

\section{Results}

Identification of the Carp Urinary Steroids by GLC

Figs. 1 and 2 show examples of the GLC separations of carp urinary steroids on $1 \% \mathrm{OV}-1$ and 


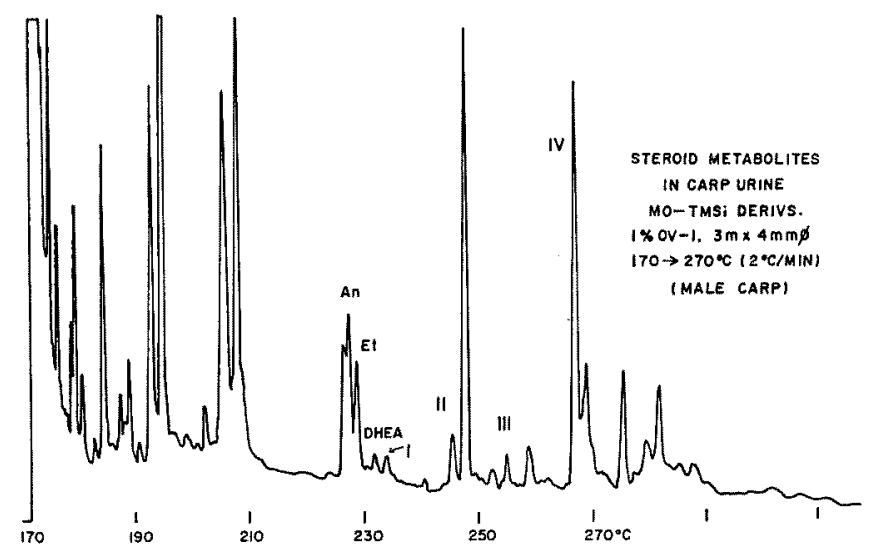

Fig. 1. Gas liquid chromatogram of carp urinary steroids as TMSi and MO-TMSi derivatives. Separation conditions: $3 \mathrm{~m} \times 4 \mathrm{~mm}$ i.d. glass column, $1 \% \mathrm{OV}-1$ on $80-100$ mesh Shimalite W, temperature programmed at $2^{\circ} \mathrm{C} / \mathrm{min}$ from $170^{\circ} \mathrm{C}$. Peaks I, II, III and IV correspond in MU value to androstenediol, pregnanediol, pregnanetriol and cholesterol, respectively. An, androsterone; Et, etiocholanolone; DHEA, dehydroepiandrosterone.

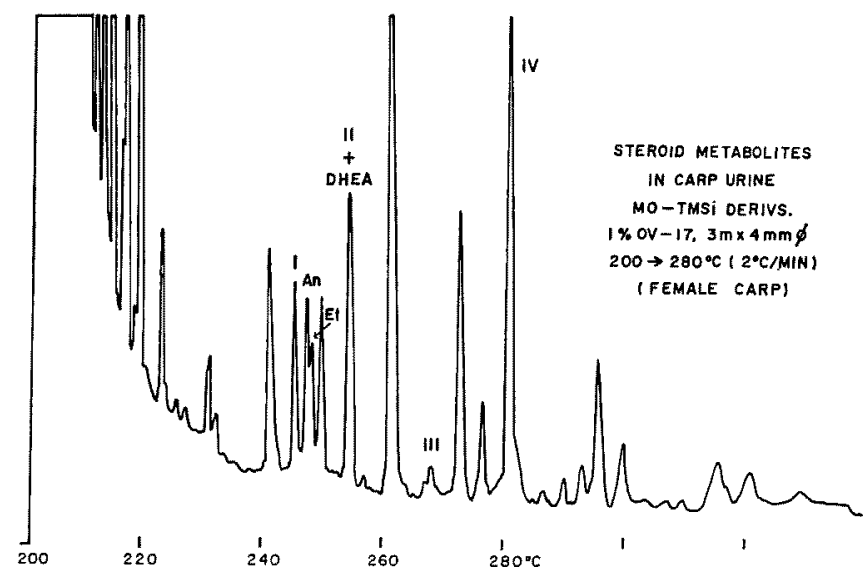

Fig. 2. Gas liquid chromatogram of carp urinary steroids as TMSi and MO-TMSi derivatives. Separation conditions are the same as for Fig. 1, except that a $1 \%$ OV-17 (on $80-100$ mesh Shimalite W) column was used, and initial temperature was $200^{\circ} \mathrm{C}$. Peaks I, II, III and IV correspond in MU value to androstenediol, pregnanediol, pregnanetriol and cholesterol, respectively. Peak II is overlapped with the peak of DHEA.

$1 \%$ OV-17 columns. The peaks in the 17 -ketosteroid region are those of androsterone (An), etiocholanolone $(E t)$ and dehydroepiandrosterone (DHEA) as identified in our previous paper.

MU values of compound I, II, III and IV on each chromatogram were compared with those of reference steroids. As shown in Table 1, compound I corresponds in $\mathrm{MU}$ value to authentic androstenediol, compound II to pregnanediol, compound III to pregnanetriol and compound IV to cholesterol, respectively. In Fig. 2, the peak of compound II is overlapped with that of DHEA.

The peak of pregnanediol was relatively high and constant in all the samples, whereas that of pregnanetriol was low and varied greatly; some samples did not contain this steroid. The amount of androstenediol also showed wide individual variations: In some samples it exceeded the amount of androsterone and in other samples it was below the amount of DHEA. On the other 
Table 1. Methylene unit (MU) values for MO-TMSi derivatives of carp urinary steroids and reference steroids determined by temperature programming with $O V-1$ and $O V-17$ liquid phases

\begin{tabular}{|c|c|c|c|}
\hline & \multirow{2}{*}{ Steroid } & \multicolumn{2}{|c|}{ Liquid phase } \\
\hline & & OV $-1 * 1$ & OV $-17^{* 2}$ \\
\hline & Compound $\mathrm{I}$ & 25.84 & 26.81 \\
\hline & Compound II & 27.58 & 28.30 \\
\hline & Compound III & 29.06 & 30.11 \\
\hline & Compound IV & 30.77 & 32.10 \\
\hline & Androstenediol & 25.84 & 26.80 \\
\hline & Pregnanediol*4 & 27.58 & 28.32 \\
\hline & Pregnanetriol*5 & 29.05 & 30.14 \\
\hline & Cholesterol & 30.80 & 32.09 \\
\hline & \multicolumn{3}{|c|}{$\begin{array}{l}1 \% \text { OV-1 column, temperature programmed at } 2^{\circ} \mathrm{C} / \mathrm{min} \text {, } \\
\text { starting at } 170^{\circ} \mathrm{C} \text {. }\end{array}$} \\
\hline *2 & \multicolumn{3}{|c|}{$1 \%$ oV-17 column temperature programmed at $2^{\circ} \mathrm{C} / \mathrm{min}$, } \\
\hline$* 3$ & \multicolumn{3}{|c|}{ starting at $200^{\circ} \mathrm{C}$. } \\
\hline *4 & & & \\
\hline *5 & \multicolumn{3}{|c|}{ 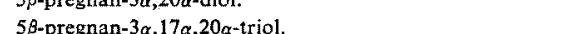 } \\
\hline
\end{tabular}

hand, no significant difference was observed in the chromatographic patterns between male and female carps. Free steroid was not found in any significant amount except cholesterol (a precursor of steroid hormones), which appeared considerably in free form.

\section{Identification of the Carp Urinary Steroids by GLC-MS}

Fig. 3 shows the mass spectrum of compound I, which coincided with that of authentic androstenediol TMSi derivative, giving molecular peak at $m / e$ 434. The loss of 90 and $90 \times 2$ mass units, due to cleavages of trimethylsilyl ether groups, results in major peaks at $m / e 344$ and 254. Peaks at $m / e 419$ (M-15), 329 (M-90-15) and 239 (M-9090-15) are due to subsequent cleavages of methyl groups.

Fig. 4 shows the mass spectrum of compound II, which coincided with that of authentic pregnanediol TMSi derivative. The peaks correspond to M, M-90, M-90-90 are seen at $m / e 464,374$ and 284, respectively. Peaks at $m / e 449(\mathrm{M}-15), 359$ (M-90-15) and 269 (M-90-90-15) are due to sub-

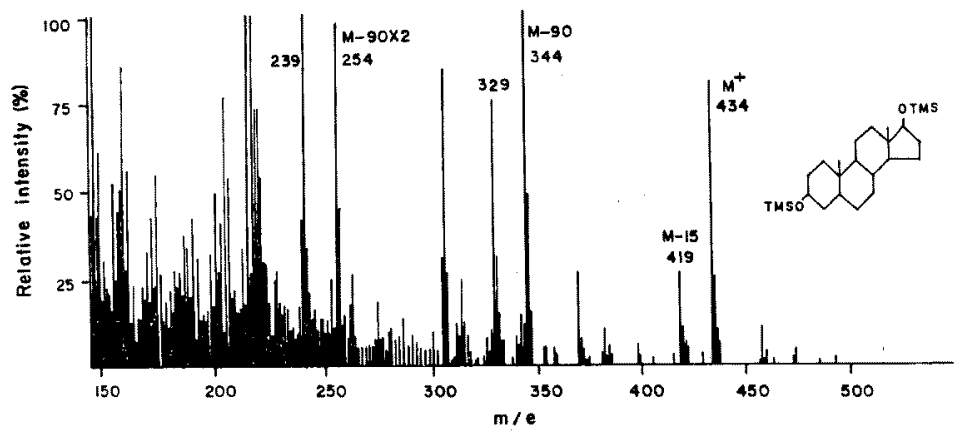

Fig. 3. Mass spectrum of compound $I$. The fragmentation pattern was identical with that of authentic androstenediol TMSi derivative. The GLC column was a $2 \mathrm{~m} \times 4 \mathrm{~mm}$ i.d. glass coil packed with $1 \% \mathrm{OV}-1$ on Shimalite W. The column temperature was programmed at $1^{\circ} \mathrm{C} / \mathrm{min}$ from $130^{\circ} \mathrm{C}$ to $230^{\circ} \mathrm{C}$.

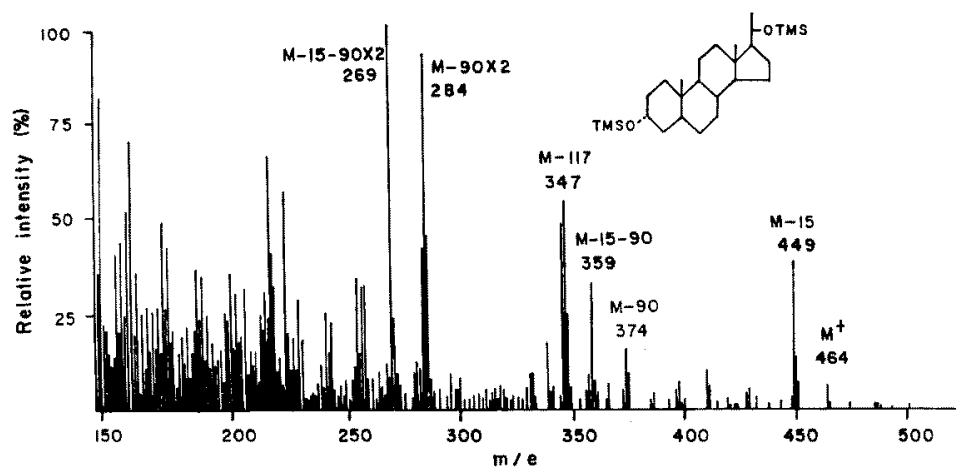

Fig. 4. Mass spectrum of compound II. The fragmentation pattern was identical with that of authentic pregnanediol TMSi derivative. GLC-MS conditions as in Fig. 3. 


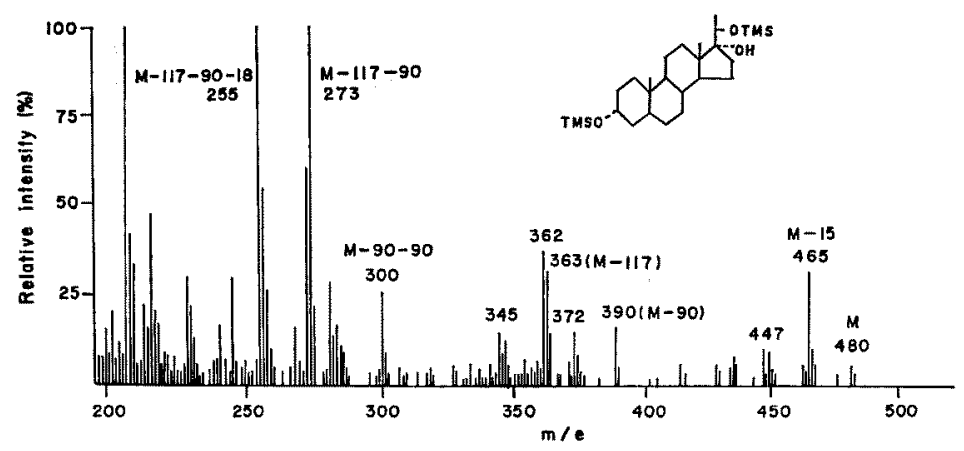

Fig. 5. Mass spectrum of compound III. The fragmentation pattern was identical with that of authentic pregnanetriol TMSi derivative. GLC-MS conditions as in Fig. 3.

sequent losses of methyl groups. The loss of the entire side chain is indicated by the peak at $m / e 347$ (M-117).

Fig. 5 shows the mass spectrum of compound III, which coincided with that of authentic pregnanetriol TMSi derivative, giving molecular ion peak at $m / e 480$. The silylation procedure employed in this paper did not convert the tertiary $17 \alpha$-hydroxyl group to an ether ${ }^{31}$. The peaks at $m / e 390(\mathrm{M}-90)$ and $300(\mathrm{M}-90-90)$ correspond to the losses of one and two molecules of trimethylsilanol. The loss of the entire side chain is indicated by successive peaks at $m / e 363$ (M-117), 345 (M-11718), 273 (M-117-90) and 255 (M-117-90-18). The loss of 18 mass units results from the elimination of water.

The mass spectrum of compound IV was completely identical with that of authentic cholesterol TMSi derivative, yielding characteristic peaks at $m / e 458$ (M), 443 (M-15), 368 (M-90), 353 (M-15$90)$ and $329(\mathrm{M}-15-114)$.

\section{Discussions}

Progesterone is produced in mammalian endocrine organs such as placenta, ovary (corpus luteum), adrenal cortex and testis, and can be readily converted by the liver to saturated pregnane derivatives which are conjugated with glucuronic acid and ultimately excreted via the kidney and the gall bladder ${ }^{9}$. To the authors knowledge there have been no intensive studies of the catabolism of progesterone in organs or tissues of fish except a report of Arai et al. ${ }^{101}$, who identified $5 \alpha$ - and $5 \beta$-pregnanedione, $3 \alpha$ - and $3 \beta$-hydroxy-5 $\alpha$-pregnan-20-one, and $3 \alpha$ - and $3 \beta$-hydroxy-5 $\beta$-pregnan20 -one as progesterone metabolites in vitro of kidney tissue of rainbow trout.

The present paper revealed the presence of pregnanediol, pregnanetriol and androstenediol in carp urine. This suggests that the metabolic pathway which involves the following sequences exists in carp as in mammals.

1) Progesterone $\rightarrow$ pregnanedione $\rightarrow$ pregnanolone $\rightarrow$ pregnanediol

2) Progesterone $\rightarrow 17 \alpha$-OH-progesterone $\rightarrow$ pregnanetriol

3) Dehydroepiandrosterone $\rightarrow$ androstenediol

Other steroids such as pregnanolone, pregnenediol, pregnenetriol and pregnenetriolone were not detected, probably because of their minor quantities.

Of the four steroids analyzed in this paper, pregnanediol and pregnanetriol were excreted as glucuronides, because they were completely liberated by hydrolysis with $\beta$-glucuronidase, whereas androstenediol both as a glucuronide and as a sulfate, because its complete liberation could be attained by solvolysis after enzymatic hydrolysis. It is of interest that considerable amount of cholesterol appeared in free form. This indicates that steroids other than metabolites are not necessarily conjugated with glucuronic acid or sulfuric acid in renal excretion.

\section{Acknowledgement}

The authors wish to thank Dr. K. KoBAYAshI, Kyushu University, for his many useful suggestions.

\section{Reference}

1) W. L. Gardiner and E. C. Horning: Biochim. Biophys. Acta, 115, 524-526 (1966). 
2) E. C. Horning, M. G. Horning, N. Ikekawa, E. M. Chambaz, P. I. JaAkonmaki, and C. J. W. Brooks: J. Gas Chromatog., 5, 283-289 (1967).

3) E. C. Horning and M. G. Horning: Methods in Medical Research, 12, 372-384 (1970).

4) R. RyhaGe: Anal. Chem., 36, 759-764 (1964).

5) T. Yano and S. IsHo: Bull. Japan. Soc. Sci. Fish., 44, 1023-1028 (1978).

6) A. L. Grafflin: Am. J. Physiol., 97, 602-610
(1931).

7) H. L. BladLow: Steroids, 11, 265-272 (1968).

8) N. SAKAUCHI: Strides of Medicine, 76, 749-753 (1971).

9) K. IWAI: in "Biochemistry of Diseases" (ed. by S. Shimazono et al.), Vol. 11(A), Nakayama Pub. Co., Tokyo, 1967, pp. 37-44.

10) R. Arai, H. Tajima, and B. Tamaoki: Gen. Comp. Endocrinol., 12, 99-109 (1969). 